\title{
Groundwater pollution: Are we monitoring appropriate parameters?
}

\author{
Gideon Tredoux ${ }^{1 *}$, Lisa Cavé ${ }^{2}$ and Pannie Engelbrecht ${ }^{1}$ \\ ${ }^{1}$ Water Programme, Environmentek, CSIR, PO Box 320, 7599 Stellenbosch, South Africa \\ ${ }^{2}$ Department of Geology, University of New Brunswick, Fredericton, Canada
}

\begin{abstract}
Groundwater pollution is a worldwide phenomenon with potentially disastrous consequences. Prevention of pollution is the ideal approach. However, in practice groundwater quality monitoring is the main tool for timely detection of pollutants and protection of groundwater resources. Monitoring groundwater quality is a specialised task for a hydrogeologist and a water quality monitoring expert. Although general prescriptions for waste management facilities exist these may not be applicable in all cases. In the literature, divergent approaches have identified various sets of pollutants and pollution indicators. This paper discusses international and local trends in groundwater monitoring for baseline studies and on-going pollution detection monitoring for a variety of situations. Cemeteries, a pollution source for which no local monitoring requirements exist, are also included. The effectiveness of some commonly prescribed monitoring parameters is considered, as well as the use of "bulk parameters" for reducing the number of analyses and the associated costs, while still achieving the optimum result. Although not considered in detail in this paper, cost-effective groundwater quality monitoring should be a key part of the design of a monitoring programme.
\end{abstract}

\section{Introduction}

Groundwater pollution threatens many valuable water resources. The consequences are often more serious than for surface water due to the relatively long subsurface residence times. Also, groundwater pollution may go undetected for years, while remediation is difficult and costly, or sometimes even impossible. For the lay person, groundwater is an elusive entity shrouded in mystery and generally out of sight and out of mind. Any attempt to evaluate groundwater pollution, requires an understanding of the particular aquifer system, its recharge and pollution pathways. Using this information, a conceptual hydrogeological model can be formulated and only then can a groundwater monitoring network be designed.

Groundwater pollution occurs widely from a variety of anthropogenic sources. These include point sources such as waste disposal facilities, industrial pollution, wastewater treatment works, on site sanitation, cemeteries and many others. Diffuse pollution includes agricultural practices, atmospheric fallout and other sources. Changes in land use, such as the clearing of vegetation, overabstraction of groundwater, or excavation below the water table, can also contribute significantly to groundwater pollution.

A large number of inorganic, organic and microbiological pollutants have been detected in groundwater because of polluting activities. The chemical and hydrological changes caused by such activities can also mobilise groundwater constituents that were originally present in the aquifer. With such a cocktail of pollutants that may occur at a contaminated site, the question arises: Which parameters should be monitored for pollution detection, and at what frequency? Should inorganic and organic chemical constituents, physical variables, isotopes, and other parameters be included?

This paper was originally presented at the 2004 Water Institute of South Africa (WISA) Biennial Conference, Cape Town, South Africa, 2-6 May 2004.

* To whom all correspondence should be addressed.

푱+2721 888-2591; fax: +2721 888-2682; e-mail: gtredoux@csir.co.za
For certain practices, such as waste management, monitoring procedures and parameters are prescribed by the authorities. The system of issuing permits or licences provides a certain degree of flexibility for stipulating the analytical parameters to be monitored but the question remains whether these are the most effective in detecting pollution. Experience has shown that a site-specific approach is often needed, rather than a generalised procedure for a certain type of activity.

The aim of this paper is to address groundwater pollution in general, but in view of the wealth of information available on waste disposal facilities, and specifically landfills, this aspect is considered in more detail. The information gained from this field could provide guidelines for handling other polluting activities.

\section{Background}

As groundwater occurs in a variety of aquifer types, the flow regime will generally differ in each situation and any particular pollution event will need to be assessed in the specific context. In addition, physical, hydrogeochemical and biogeochemical processes in the subsurface may remove or modify the pollutants.

\section{Aquifer types}

Three main aquifer types are generally recognised (see for example DWAF, 1998):

- Porous or "primary" aquifers

- Fractured or "secondary" aquifers

- Dolomitic aquifers

A primary aquifer could consist of unconsolidated material (e.g. in an alluvial bed) or be cemented (e.g. by calcium carbonate). It could also be fully consolidated (e.g. as a sandstone) and then also be fractured due to tectonic activity. In such cases the groundwater flow is complicated due to the so-called "double porosity" in the aquifer. The aquifer types often occur in combination with a primary aquifer (e.g. soil or weathered material) covering a second- 
ary aquifer. Dolomitic aquifers are secondary aquifers as they generally develop a fracture system, which is then eroded by chemical dissolution to form large cavities. Calcrete is subject to similar processes. All these types of aquifers and their combinations lead to distinctly different flow patterns while water-rock interaction and it effects on water quality will differ significantly. Another key question in groundwater pollution is whether the aquifer is protected by confining layers. Penetrating impermeable layers for monitoring purposes may put a deeper aquifer at risk, if the borehole is inadequately sealed through the polluted section. In view of the complex nature of aquifers it is imperative that for each specific situation a competent hydrogeologist is engaged to set up a groundwater quality monitoring system in association with a pollution monitoring expert.

\section{Pollutant removal and modification}

When searching for pollutants, it has to be recognised that various processes (including adsorption, ion exchange and biodegradation), remove substitute or decompose pollutants during transport through the subsurface. It may be necessary to look for the products or substitutes of the original pollutants. The thickness of the unsaturated zone, type of aquifer or combination of aquifers, flow rate, and other factors will determine the extent of pollutant transformation.

Removal and transformation of inorganic pollutants are relatively well known and understood. For organic pollutants, biogeochemical processes occurring during subsurface transport are a major factor determining the presence and concentration of the resultant compounds (Barber, 1992).

\section{Detecting pollution and identifying pollutants}

Detecting and confirming pollution is the first step to a more detailed study of any specific pollution situation. For various reasons, detecting pollution in groundwater systems is difficult, for example due to the complex nature of groundwater flow, the natural variability of constituent concentrations in aquifers, and the problem of obtaining a representative groundwater sample. Generally, time series and other graphical techniques are used to identify groundwater quality changes in time and space that may be linked to pollution.

Pollutant transport into the aquifer is directly linked to groundwater recharge, natural or artificial, and the presence of liquid is a key factor in the pollution process. For this reason, pollutants from wastewater discharges have a higher probability of reaching the aquifer than those from a point source with lower moisture content.

Minimum requirements for water monitoring at waste management facilities are set out by the Department of Water Affairs and Forestry (DWAF, 1998). A range of potentially polluting activities are included, e.g. mining, power generation (coal fired power stations), waste disposal sites (general and hazardous), sewage treatment and sludge disposal, wastewater irrigation, on site sanitation, agriculture (feed-lots and diffuse sources), urban development, underground storage tanks, and industries. This publication gives a good overview of the potential groundwater impacts and the minimum requirements generally applicable. It also recommends general monitoring frequencies and parameters to be determined. Depending on the study requirements, it may be important to carry out field determinations for electrical conductivity (EC) and unstable parameters such as $\mathrm{pH}$, redox potential (Eh), temperature and dissolved oxygen (DO). A number of other field measurements of constituent concentrations may be required, e.g. for hydrochemical modelling. Gases, e.g. hydrogen sulphide or methane may be detected semi quantitatively by means of Draeger tubes. Tritium $\left({ }^{3} \mathrm{H}\right)$ has been found to occur at high levels at certain waste disposal facilities (Verhagen et al., 1998) and could play a key role in special situations for detecting pollution. The cost of tritium analyses, however, may be prohibitive for general use where common, inexpensive chemical measurements could provide the necessary answers.

Key activities that potentially can pollute groundwater, such as wastewater treatment and disposal, landfilling, and cemeteries, are reviewed, below and proposals for detecting pollution are discussed. These should serve as examples for developing groundwater quality monitoring protocols.

\section{Sewage treatment and disposal}

In a study of a groundwater pollution plume caused by sewage infiltration in the USA, Barber (1992) developed approaches for screening and detailed investigation of the pollution. For the initial detection of the pollution plume, the parameters used were chloride, boron, EC, and dissolved organic carbon (DOC). Chloride (and bromide) are conservative ions, i.e. they do not enter into redox reactions, adsorb significantly onto mineral surfaces, form complexes with other ions, or undergo transformations that remove the ions from solution. Similarly, boron does not undergo redox transformations, biological degradation, precipitation or significant sorption. The conservative ions are the first species to break through when a plume moves through a porous medium and so should be the first to be detected at the edges of the moving plume. In contrast, other non-conservative parameters, such as nitrate, sulphate, bicarbonate, phosphate, ammonium, calcium, magnesium and potassium, undergo chemical reactions in solution, are adsorbed onto the aquifer material or are biologically transformed. These move slower than the conservative species and are usually found at a later time or closer to the pollution source.

In the colder regions, $\mathrm{NaCl}$ de-icing of roads could add significant amounts of chloride to the groundwater and interfere with the tracing of the pollution plume (Barber, 1992). For this reason, boron is the preferred tracer as it is ubiquitous in sewage effluents and has restricted natural and anthropogenic sources. The major source of boron in sewage is sodium perborate used as bleach in detergent powders and the boron concentration in the final effluent typically varies between 0.3 and $1.5 \mathrm{mg} / \ell$. Natural groundwater in the USA study area had a boron concentration $<20$ to $50 \mu \mathrm{g} / \ell$ while contaminated groundwater had 90 to $530 \mu \mathrm{g} / \ell$ (Barber, 1992). When checked for boron, Cape Town sewage was found to have relatively high boron concentrations in sewage sludge (King, 2004), but no recent data were available for this parameter for the final effluent from the various treatment plants. The concentrations of pollutants in sewage sludge are controlled in terms of regulations issued in 1991 by DWAF (1991) and later guidelines jointly issued by several government departments (WRC et al., 2002).

Primary and secondary sewage treatment reduces the DOC (i.e. the "bulk" organic parameter) of the effluent by 80 to $90 \%$. The selective removal of more easily biodegradable compounds in these processes yields treated effluent containing relatively recalcitrant and mobile organic compounds (Barber, 1992). However, during infiltration, DOC is further reduced in the unsaturated zone by biodegradation and sorption to the sediments. The bulk parameter DOC itself gives no indication as to the nature of the organic compounds and, as a first step, Barber (1992) subjected the wide 
range of compounds to extraction to obtain hydrophobic and hydrophilic fractions. Each of these was then further subdivided into acid, neutral and basic fractions. In addition, methylene-blueactive substances were determined as well as volatile halogenated organic compounds (VOX). VOX compounds, particularly the chlorinated species, are amongst the most commonly detected organic pollutants in groundwater (Barber, 1992).

\section{Landfills}

For landfills, Kerndorff et al. (1992) developed a methodology based on the ratio of pollutant concentrations up and down gradient of contaminated sites. The authors used statistical data obtained from a large number of abandoned waste disposal sites in Germany, but the approach could be applied to any other point sources of contamination, provided that the affected groundwater has concentrations of pollutants that are significantly higher than background levels in the aquifer. Chemical data sets are grouped into uncontaminated (up gradient) and contaminated (down gradient) samples. Each subset is statistically analysed for each analytical parameter (e.g. potassium, dissolved organic carbon, etc.) and the results are developed further to derive contamination factors as well as a frequency of background excedence. These two statistical measures can be applied separately or in combination for characterising the pollution impact on groundwater.

\section{Contamination factors}

The contamination factor developed by Kerndorff et al. (1992) uses the ratio of the values in contaminated groundwater to those in uncontaminated groundwater. Contamination factors are calculated for the mean, maximum, median and other percentile concentrations for each analytical parameter. The purpose of using the ratios of various statistical measures is to circumvent the problem of pollutant concentrations often being below detection limits. When all uncontaminated values are below the detection limit the factor cannot be calculated for that parameter. If the waste site, or other point source, is not polluting the groundwater, the pollutant concentration down gradient should equal the up gradient concentration, yielding a contamination factor of 1 . In case of pollution, the contamination factor will be $>1$ and the greater the impact, the higher the ratio will be. Table 1 presents contamination factors for selected inorganic parameters based on median and mean concentrations (adapted from (Kerndorff et al., 1992)).

From the above it is evident that the concentrations of most common groundwater cations and anions increase during pollution events. It follows that the EC would, in general, also increase. As with sewage pollution, EC would be a useful parameter to monitor. However, EC contamination factors were not provided in the paper.

Trace constituents often do not exceed the detection limits and accordingly contamination factors could not be calculated in these cases. Nevertheless, it is evident that these constituents can reach very high concentrations as demonstrated by the factors calculated using mean values. This is also evident from the mean values of ammonium and boron. Thus, although these constituents may not serve the purpose as general tracer of pollution, they should be determined as part of the baseline data set and also for boreholes where pollution has been confirmed.

\section{Frequency of background excedence}

In an alternative approach, Kerndorff et al. (1992) ranked the individual constituents according to the frequency with which the mean background concentrations are exceeded (see Table 1).
TABLE 1

Contamination factors and detection frequency of chemical constituents in groundwater (adapted from Kerndorff et al., 1992)

\begin{tabular}{|l|c|c|c|}
\hline \multirow{2}{*}{ Parameter } & \multicolumn{2}{|c|}{$\begin{array}{c}\text { Contamination } \\
\text { factors }\end{array}$} & $\begin{array}{c}\text { Detection } \\
\text { frequency** }\end{array}$ \\
\cline { 2 - 4 } & Median & Mean & $\%$ \\
\hline Zinc & 7.2 & 9.7 & 41.2 \\
Potassium & 5.0 & 9.6 & 74.2 \\
Ammonium & 4.6 & 65.5 & 53.6 \\
Boron & 4.0 & 21.6 & 85.7 \\
Copper & 3.7 & 6.6 & 52.4 \\
Sulphate & 3.4 & 3.8 & 64.5 \\
Manganese & 3.1 & 7.6 & 62.6 \\
Sodium & 2.7 & 6.2 & 83.4 \\
Chloride & 2.6 & 5.7 & 79.2 \\
Strontium & 2.6 & 3.0 & 74.1 \\
Nitrate & 2.5 & 5.5 & 50.7 \\
Magnesium & 2.5 & 3.4 & 76.0 \\
Bicarbonate & 2.4 & 2.8 & 85.7 \\
Calcium & 2.2 & 2.3 & 74.5 \\
Fluoride & 2.2 & 1.0 & 52.6 \\
Arsenic (III, V) & $-*$ & 122.0 & 61.3 \\
Cadmium & $-*$ & 26.9 & 14.9 \\
Nitrite & $-*$ & 25.7 & 35.4 \\
Chromium & $-*$ & 15.8 & 56.3 \\
Nickel & $-*$ & 14.8 & 64.3 \\
Aluminium & $-*$ & 10.8 & 33.9 \\
\hline * more than 50\% of values below detection limit \\
** contaminated groundwater exceeding mean background \\
(uncontaminated) concentration & \\
\hline
\end{tabular}

Using this approach, it was found that boron and bicarbonate were very good tracers of leachate from waste disposal, with concentrations down gradient exceeding those up gradient of the site in $85.7 \%$ of the samples. Other inorganic substances which exceed background concentrations are (in decreasing order of frequency): sodium, chloride, magnesium, calcium, potassium, strontium, sulphate, nickel and manganese (Kerndorff et al., 1992).

\section{Characteristic pollutants}

Kerndorff et al. (1992) derived a subset of inorganic parameters that are characteristic of groundwater contamination from a particular type of source by combining the above two approaches. They used simple multiplication of contamination factors and detection frequencies to derive the following set of characteristic inorganic pollutants for abandoned waste disposal sites in Germany: arsenic, ammonium, boron, nickel, and chromium. These would undoubtedly be priority pollutants for monitoring to detect leakage from waste disposal activities. However, the contamination factors based on the mean pollutant concentrations have a large weighting while the frequency of exceeding background concentrations has a limited effect when multiplying. In this way other important constituents that occur more frequently are ignored. Furthermore, the prioritisation in this method is based only on the likelihood of occurrence in groundwater, rather than the impact of the pollution, since it does not take into account the toxicity of the substances. 


\begin{tabular}{|l|c|c|c|c|}
\hline \multicolumn{5}{|c|}{ TABLE 2 } \\
\hline \multicolumn{4}{|c|}{ Organic priority pollutants (after Schleyer et al., 1992) } \\
\hline Organic compound & $\begin{array}{c}\text { Mobility } \\
\text { potential* }\end{array}$ & $\begin{array}{c}\text { Sorption } \\
\text { potential* }\end{array}$ & $\begin{array}{c}\text { Persistence } \\
\text { potential** }\end{array}$ & $\begin{array}{c}\text { Groundwater } \\
\text { migration } \\
\text { potential* }\end{array}$ \\
\hline Trichloroethene & & & & 4470 \\
Tetrachloroethene & 59.4 & 56.7 & 77 & 4104 \\
Trichloromethane & 47.6 & 51.3 & 83 & 3208 \\
1,4-Dichlorobenzene & 71.5 & 65.0 & 47 & 2659 \\
1,3-Dichlorobenzene & 35.2 & 35.7 & 75 & 2571 \\
1,2-Dichlorobenzene & 42.6 & 35.3 & 66 & 1875 \\
Benzene & 39.4 & 35.6 & 50 & 1046 \\
Chlorobenzene & 62.6 & 53.6 & 18 & 1023 \\
Ethylbenzene & 50.7 & 42.3 & 22 & 539 \\
trans-1,2-Dichloroethene & 45.9 & 37.0 & 13 & 328 \\
Dichloromethane & 78.5 & 69.8 & 5 & 78 \\
Tetrachloromethane & 59.7 & 77.1 & 1 & 56 \\
Phenol & 54.4 & 54.1 & 1 & 1 \\
\hline * see text for explanation & & & & \\
\hline
\end{tabular}

\section{Analysis of monitoring data variance}

This data analysis technique is based on changes in monitoring data variance over time (Plumb, 1991). This method does not use the separation of samples into up- and down-gradient data sets and so avoids the implicit assumptions of how chemicals behave at the contaminated sites. The method relies on the premise that the observed concentrations of an inorganic constituent, which is not involved in a leakage event, should be similar for all monitoring boreholes at the site i.e. the variance in the data for that substance should be low. If an inorganic pollutant is released from a point source into the groundwater, the concentration will increase at one or more monitoring points and the variance in the monitoring data will also increase.

The variance in monitoring data was calculated for 16 inorganic parameters at 253 waste disposal sites in the USA (Plumb, 1991). The variance for each parameter was then categorised as low or high and the chemical parameters ranked according to the number of sites at which the variance was found to be high. Kerndorff et al. (1992) compared the results from the analysis of variance for US waste disposal sites with those for the German waste sites using contamination factors and frequency of background excedence. Notably, boron was not included in this comparison as it was not analysed routinely at the US sites. From this comparison it was concluded that for waste disposal sites arsenic, cadmium, sodium, magnesium, zinc, nickel and chloride are the specific inorganic pollutants that are most frequently detected leakage events.

In a study of groundwater pollution at waste disposal sites and a wastewater treatment works in the Cape Flats (Tredoux, 1984) key parameters that characterised the pollution included ammonium, potassium, total alkalinity and EC. For detecting groundwater pollution, the absolute concentrations of the pollutant, such as ammonium, is important while for the "bulk" parameter EC, its relative increase at the point of impact will indicate the presence of pollution.

Schleyer et al. (1992) developed a risk-based approach for deciding which parameters to analyse at landfill sites. According to these authors the risk potential of the waste site lies in the gaseous, liquid and solid emissions from the site and direct contact with the waste. According to them, liquid seepages into the groundwater pose the largest risk potential. The initial screening included two inorganic parameters, viz. boron and sulphate, and two organic parameters, viz. the adsorbable organic halogen (AOX) concentration, and a gas chromatographic "fingerprint" (number of peaks and peak area). Further investigation was carried out if these parameters significantly exceeded the regional background values.

For their detailed analysis, the following inorganic "priority pollutants" were identified and ranked according to their "hazard potential”: As, $\mathrm{Ni}, \mathrm{Cr} \mathrm{NO}_{2}, \mathrm{~Pb}, \mathrm{Cu}, \mathrm{NO}_{3}$, $\mathrm{Zn}$ and $\mathrm{Cd}$. The hazard potential was defined as the product of the standardised detection frequency, the standardised mean concentration and the toxicological evaluation number (Schleyer et al., 1992).

The organic compounds identified as "priority pollutants" are treated in a similar way, but then a further important factor, the groundwater migration potential, is used in the ranking system to account for their behaviour in the aquifer (Schleyer et al., 1992). The groundwater migration potential is calculated as the mean of the mobility potential and the sorption potential multiplied by the persistence potential. The mobility potential is the product of the standardised water solubility and the standardised vapour pressure for each compound. The sorption potential is the product of the octanol-water distribution coefficient and the first order molecular connectivity index. Both values are subtracted from 100 before multiplication. The persistence potential is defined as the mean of the standardised COD and BOD. The organic compounds and their resultant ranking are shown in Table 2.

\section{Cemeteries}

The groundwater pollution potential of cemeteries has largely been overlooked in South Africa (Engelbrecht, 1998). Planning of cemeteries generally did not take groundwater pollution into account. A study of groundwater pollution at a local cemetery has shown how the rising water tables in winter can lead to significant impacts (Engelbrecht, 1998).

The Environment Agency in the UK has published guidelines for monitoring of cemeteries (Environment Agency, 2002). At low risk sites, no monitoring is needed, but at intermediate and high risk 
sites six monthly monitoring is required for the following "indicators of contamination" once the sites are in use: (water level), $\mathrm{pH}$, temperature, EC, $\mathrm{DO}, \mathrm{NO}_{3}+\mathrm{NO}_{2}$, TOC, $\mathrm{BOD}, \mathrm{COD}$, ammoniacal nitrogen, $\mathrm{SO}_{4}, \mathrm{Cl}, \mathrm{Na}, \mathrm{K}, \mathrm{Ca}, \mathrm{Mg}, \mathrm{Fe}$ and $\mathrm{P}$.

Background monitoring at these sites is required 12 months before and also 12 months after site development for the following suite of determinands: (water level), $\mathrm{pH}$, temperature, EC, DO, $\mathrm{NH}_{4}, \mathrm{~N}$ (presumably $\mathrm{NO}_{3}+\mathrm{NO}_{2}$ ) and $\mathrm{Cl}$. These parameters are to be measured quarterly at intermediate risk sites and monthly at high risk sites. Furthermore, the following additional determinands are to be analysed six monthly at intermediate risk sites and quarterly at high risk sites: $\mathrm{SO}_{4}, \mathrm{NO}_{3}+\mathrm{NO}_{2}$, TOC, $\mathrm{BOD}, \mathrm{COD}$, alkalinity, $\mathrm{Na}, \mathrm{K}, \mathrm{Ca}, \mathrm{Mg}, \mathrm{Fe}, \mathrm{Mn}, \mathrm{Cd}, \mathrm{Cr}, \mathrm{Cu}, \mathrm{Ni}, \mathrm{Pb}, \mathrm{Zn}$ and $\mathrm{P}$.

It is noteworthy that the list of parameters for sites that are in use is shorter than for the background monitoring with, for example, alkalinity excluded for sites that are in use. In all cases, the monitoring frequency is reduced to six monthly with the possibility of further reduction to annual sampling provided "stable conditions" are proven.

\section{General}

Early attempts were made regarding the monitoring of groundwater quality on a national scale in South Africa. A strategy was proposed for this purpose and a provisional list of parameters proposed (Parsons and Tredoux, 1995). This included the parameters (temperature), EC, $\mathrm{pH}, \mathrm{Na}, \mathrm{K}, \mathrm{Mg}, \mathrm{Ca}, \mathrm{Cl}, \mathrm{SO}_{4}$, total alkalinity, $\mathrm{NH}_{4}, \mathrm{NO}_{3}+\mathrm{NO}_{2}$, and DOC. At that stage it was stated that little was known about groundwater quality on a national scale. Meanwhile the situation has changed in some respects and, at least in the case of waste management facilities, guidelines issued for groundwater monitoring (DWAF, 1998) have helped to improve the knowledge of groundwater pollutants at these facilities.

\section{Correctness and accuracy of analyses}

For all hydrochemical studies, high quality analytical work is required. Using a reputable laboratory is always essential. Whenever possible, quality checks should be carried out, e.g. include unidentified duplicate samples, and if sufficient parameters are determined, calculate an ionic balance. It is also possible to compare the measured EC with a calculated value based on the sum of the specific conductivities of the individual ions. If a problem is suspected with a particular parameter, a spiked sample with a known concentration can also be submitted to the laboratory as a quality check. Determining only a few parameters that do not allow calculation of an ionic balance is risky unless a good data base of water quality analyses is available.

Despite all precautions outlined in sampling and analytical method manuals, it still happens that incorrect results are obtained, e.g. a trace metal or organic parameter may be reported when none is present. This happens especially with mercury, due to the practice of prescribing mercury addition for sample preservation and the very low levels of detection required. For parameters that are usually reported in micrograms per litre $(\mu \mathrm{g} / \ell$, or parts per billion) the risk of false positives is high if the sampling and laboratory procedures to control contamination are not rigorously enforced.

\section{Discussion}

Most aquifers are vulnerable and the range of potential pollutants in groundwater is vast. Inorganic constituents are many, but organic chemicals are increasing by the thousands each year. The Chemical Abstract Service registry now contains records for more than 22 million organic and inorganic substances (http:// www.cas.org/ February (2004)). Certainly, not all of these will occur in measurable quantities in groundwater, but the large number of potential pollutants indicates the problem of detecting and identifying chemical compounds in the environment.

For pollution assessment, the natural background situation has to be recorded before the event. Alternatively, after the event the background water quality has to be determined in an unpolluted area, hydraulically up-gradient from the pollution source. In the ideal case, and if the source is a landfill, a detailed assessment of the unpolluted environment will include data on the occurrence of the characteristic pollutants as defined by Kerndorff et al. (1992) and the priority pollutants identified by Schleyer et al. (1992). In the arid and semiarid regions the background data is even more important as the concentrations of most constituents, including chloride and boron, in natural groundwater are often higher than in the humid areas. Boron occurs naturally at levels that approach those accepted as "contaminated" in other areas. In other parts of the world, trace constituents, such as arsenic, occur naturally in certain sediments. Changes in redox conditions during groundwater abstraction may mobilise the arsenic and it will occur in otherwise unpolluted water. In all cases, the compilation of a data base for the chemical parameters is essential for early identification of changes, including data on the common groundwater constituents, i.e. nonpollutants.

The various approaches described in the literature vary but for a first screening there seems to be agreement that the common inorganic constituents can give a clear indication of pollution in the aquifer. EC measurements, which can easily be performed in the field, are extremely useful in identifying changes in salinity that accompany most inorganic pollution events. Provided the general direction of groundwater flow is known, it could be possible to confirm the occurrence of pollution at the particular point source. The additional analysis of parameters such as boron and a "bulk" organic parameter such as DOC will provide further proof of the pollution event. In the case of a pure organic spill, e.g. solvents, it may be necessary to use soil-gas sampling or redox measurements as screening tools. Analysis of chemical oxygen demand (COD) is often prescribed in regulations and permit conditions, presumably as a (organic?) "pollution indicator” parameter. This can be useful, provided it is realised that the oxygen demand also relates to natural inorganic constituents existing in reduced form in (deeper parts of) the aquifer. At low values (i.e. $<<50 \mathrm{mg} / \ell$, and certainly at $<10$ $\mathrm{mg} / \ell$ ) the COD determination is not necessarily accurate. Then the dissolved organic carbon (DOC) provides a more accurate indication of (organic) constituents in the water.

Groundwater quality monitoring can have large cost implications, both with respect to sampling and analysis. Although this paper does not investigate these costs, groundwater quality monitoring decisions has to take it into consideration in one way or another. On the one hand, aquifers should be protected practically at all costs as the cleanup after pollution events have huge cost implications. On the other hand, the cost has to be economically justifiable. Not all aquifers are that valuable due to salinity, poor yield or other factors. Therefore, the monitoring needs, including the parameters to be analysed, should be linked to the present groundwater use or more generally to the aquifer potential. The economic value of the aquifer should be determined on a rational basis, e.g. using an aquifer system management classification, such as that developed by Parsons (1995), followed by a calculation of the cost involved should the aquifer be lost. 


\section{Conclusions}

Identifying and quantifying groundwater pollution needs an aquifer specific, site specific and pollutant specific approach in a joint effort by hydrogeologists and pollution monitoring experts. In this approach, the conceptual hydrogeology, the monitoring network and the parameters for monitoring will be defined.

However, "bulk parameters" such as electrical conductivity and dissolved organic carbon are extremely useful tools for delineating pollution plumes. Electrical conductivity in particular, can easily be determined in the field and in the majority of cases will give a reliable indication of the extent of the problem.

For determining the background values, groundwater quality monitoring at a hazardous waste facility, initially requires analysis of the full list of frequently occurring characteristic pollutants, as well as all additional priority pollutants and organic compounds with a high migration potential. At the same time, the common cations and anions should be included and used for delineating pollution plumes. Unless specific hazardous substances are detected, the common constituents can be analysed more regularly than the special pollutants. Until pollution is detected, the list of determinands can be shortened significantly by only analysing for key constituents such as EC, boron, sodium, chloride and potassium. In the case of non-hazardous waste facilities, the common constituents may form the bulk of the analytes, and this would significantly reduce the monitoring costs. At hazardous waste disposal sites the organic priority pollutants trichloroethene, tetrachloroethene, trichloromethane, and the dichlorobenzene isomers should be included in the regular detection monitoring programme.

For detecting sewage pollution, boron, chloride and electrical conductivity are the key indicators with regard to inorganic compounds and dissolved organic carbon for organic compounds. When the dissolved organic carbon concentration is high, or if it persists in time and space, it should be subdivided into hydrophilic and hydrophobic fractions for further study of the organic components.

In the case of cemeteries, the British monitoring guidelines could be used as a first approach for detecting the groundwater impacts.

\section{References}

BARBER LB (1992) Hierarchical analytical approach to evaluating the transport and biogeochemical fate of organic compounds in sewagecontaminated groundwater, Cape Cod, Massachusetts. In: Lesage S and Jackson RE (ed.) Groundwater Contamination and Analysis at Hazardous Waste Sites. Marcel Dekker Inc., New York. 73-120.

DEPARTMENT OF WATER AFFAIRS AND FORESTRY (DWAF) (1998) Waste Management Series. Minimum Requirements for Water Monitoring at Waste Management Facilities (2nd edn.).

DEPARTMENT OF WATER AFFAIRS AND FORESTRY (DWAF) (1991) Permissible Utilisation and Disposal of Sewage Sludge.

ENGELBRECHT JFP (1998) Groundwater pollution from cemeteries. WISA Biennial Conference and Exhibition, Cape Town, May.

ENVIRONMENT AGENCY (2002) Assessing the groundwater pollution potential of cemetery developments. National Groundwater \& Contaminated Land Centre, Bristol BS32 4UD, United Kingdom. 20 pp. http://www.cas.org/ February (2004).

KERNDORFF H, SCHLEYER R, MILDE G and PLUMB RH (Jr.) (1992) Geochemistry of groundwater pollutants at German Waste Disposal Sites. In: Lesage S and Jackson RE (ed.) Groundwater Contamination and Analysis at Hazardous Waste Sites. Marcel Dekker Inc., New York. 245-271.

KING PB (2004) City of Cape Town, E-mail Communication, February. PARSONS R (1995) A South African Aquifer System Management Classification. Water Research Commission Report No KV 77/95.

PARSONS RP and TREDOUX G (1995) Monitoring groundwater quality in South Africa: Development of a national strategy. Water SA 21(2) 113-116.

PLUMB RH (Jr.) (1991) Characterizing disposal site leakage events through changes in monitoring data variance. Presented at the ASTM Symposium on Ground Water Monitoring, San Diego, CA, 31 Jan 1991. Cited in Kerndorff et al. (1992).

SCHLEYER R, KERNDORFF H and MILDE G (1992) Detection and evaluation of groundwater contamination caused by waste sites. In: Lesage S and Jackson RE (ed.) Groundwater Contamination and Analysis at Hazardous Waste Sites. Marcel Dekker Inc., New York. 273-291.

TREDOUX G (1984) The groundwater pollution hazard in the Cape Flats. Water Pollut. Control 83 473-483.

VERHAGEN BT, LEVIN M and FOURIE A (1998) High level tritium in leachate from landfill sites in the Republic of South Africa with emphasis on its distribution and value as an environmental tracer. WISA Biennial Conference and Exhibition, Cape Town, May.

WRC et al. (2002) Addendum to the Guideline on Permissible Utilisation and Disposal of Sewage Sludge Edition 1, Compiled jointly by Water Research Commission and Dept of Water Affairs \& Forestry, Dept of Agriculture, Dept of Health. 